\title{
Don Quijote y el exilio: La representación del Hidalgo Caballero en la plástica del artista aragonés Eleuterio Blasco Ferrer
}

\author{
RUBÉN PÉREZ MORENO*
}

\section{HACIA EL EXILIO}

Con la ofensiva sobre Cataluña iniciada el 23 de diciembre de 1938, y la caída de Tarragona el 14 de enero de 1939 y Barcelona el 26 del mismo mes, se aceleró un éxodo sin precedente en la Historia de España. En total, cerca de 500.000 personas habían atravesado la frontera a comienzos de 1939. Se puede decir que es el 14 de febrero la fecha en la que, momentáneamente, Francia presentaría mayor número de refugiados españoles, habiendo ya accedido prácticamente todos ellos ${ }^{1}$.

Se iniciaba así la primera de las cinco etapas en que Louis Stein divide la odisea de los republicanos españoles en Francia. La primera de febrero a septiembre de 1939, la del éxodo e internamiento de los refugiados en los campos; la segunda desde el inicio de la Segunda Guerra Mundial, en sep-

* Universidad de Zaragoza.

1. Es importante dejar claro que la mayor parte de este aluvión de españoles que atraviesan la frontera en los últimos meses de la guerra, no lo han hecho con el verdadero propósito de exiliarse, sino mas bien empujados por los acontecimientos bélicos, de manera excepcional y temporal. De hecho, ya en las primeras semanas de febrero, y concretamente entre el 1 y el 19, se repatrían a razón de 3500 personas al día por la frontera de Irún. El fenómeno es complejo y no ha lugar en este estudio, pero ha de notarse como esta masa de españoles se reducirá con cierta rapidez, bien por las repatriaciones a España, bien por la diáspora a otros países y continentes, lo que decantará la verdadera emigración a Francia con motivo de la Guerra Civil en alrededor de 180.000 o 190.000 personas, según autores. Los trabajos más rigurosos en este sentido son los realizados por Javier Rubio (1974, 1977). Louis Stein (1983) señala que las repatriaciones en 1939 deben estar comprendidas entre dos estimaciones, de 150.000 a 200.000, aunque señala datos de hasta 350.000. Por su parte, Caudet (1997) da un cómputo final de alrededor de 300.000 exiliados republicanos tras el regreso en los primeros meses de unos 200.000 republicanos a España. 
tiembre de 1939, hasta la derrota francesa y el armisticio, en julio de 1940, período en el que los republicanos españoles pasan a las filas del ejército francés, son asignados a batallones de trabajo o trabajan en la agricultura e industria francesa; la tercera, de julio de 1940 a mayo de 1945, los españoles republicanos son de nuevo organizados en batallones de trabajo por el Gobierno de Vichy, siendo obligados a trabajar para Alemania, organizándose el Movimiento de Resistencia o pasando a engrosar las Fuerzas Militares Francesas Libres, cayendo en manos de los nazis y acabando en los campos de concentración un buen número de ellos; la cuarta de mayo de 1945 a diciembre de 1955, momento en que se pedía a gritos la ayuda aliada para derrocar a Franco, hasta que las expectativas se vieron frustradas por la coyuntura internacional; la quinta desde 1955 a 1975, donde la llama antifranquista siempre estuvo presente, mientras poco a poco, aquellos exiliados iban muriendo tras los años de abandono, sufrimiento y frustración (Stein, 1983: 17).

El artista aragonés Eleuterio Blasco Ferrer (Foz-Calanda, Teruel, 1907-A1-

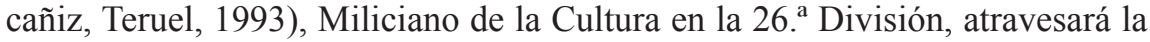
frontera franco-española el 10 de febrero de 1939. Tras pasar por el centro de clasificación de Latour-de Carol y el Castillo de Mont Louis, fue internado, como el resto de compañeros de la división anarquista, en el campo de concentración de Vernet d'Ariège. El focino se hallaba trabajando en una fábrica de bombas y material bélico en Burdeos a la llegada de las tropas nazis. Pero no tardará en instalarse en París, en 1942, continuando una prolífica carrera en suelo galo que no se vio interrumpida o fracturada por la Guerra Civil (Pérez Moreno, 2014).

\section{DON QUIJOTE COMO SÍMBOLO DEL EXILIO REPUBLICANO}

La cultura anarquista en el exilio presentó siempre un carácter popular y autodidacta, donde sus miembros recreaban y transmitían los ideales, valores e iconos que la representaban. El Conocimiento, la Verdad, la Razón, la Justicia (Alted, 2005: 116); Hércules, Bakunin, Ferrer i Guardia, se convierten en verdaderos modelos. Especial importancia cobra la representación de don Quijote arremetiendo contra los molinos de viento, una imagen como instrumento de formación especialmente simbólica para el exilio en general. Miguel de Cervantes fue un verdadero icono que sobresalió por encima de otros pensadores, escritores, músicos o políticos como Bakunin, Eliseo Reclús, León Tólstoi, Balzac, Stefan Zweig, Beethoven, Dostoyevski, Ferrer i Guardia, Malatesta, etc. En cualquier biblioteca anarquista no faltó nunca el libro El Ingenioso Hidalgo don Quijote de la Mancha. Como escribió Federica Montseny en el calendario de 1988 que SIA dedicó a Cervantes: 
Don Quijote de la Mancha, obra fundamental de Cervantes, ha sido y es el espíritu de aventura, la lucha por la justicia y la exaltación de la personalidad del hombre... Don Quijote es el pensamiento profundo que a veces toma apariencias de locura. Pero Cervantes (pacifista por excelencia, enemigo de la fuerza) tuvo la inteligencia de colocar a su lado como símbolo de prudencia y del buen sentido popular, la figura del inimitable Sancho Panza, que es el pueblo... (Alted, 2012: 173)

La identificación con el hidalgo cervantino y su asociación con algunos de los valores que encarna, como el idealismo, la sinceridad y el noble peregrinar, se generalizó en la cultura del exilio al emparentarse con las andanzas de aquellos españoles durante la guerra y su periplo como expatriados:

Son los nuevos e ilustres Quijotes

del siglo presente y venideros.

Son los que lucharon

por toda una era de paz y progreso.

Son los visionarios,

los locos modernos

que a los nuevos Atilas y Marte (Redondo, 2009: 216)².

La atracción por parte de intelectuales y artistas hacia don Quijote (aunque no en todos los casos hay una identificación clara y directa entre la representación del hidalgo y la condición de exiliado), con sus ideales e ilusiones, le convirtieron, como apunta Miguel Cabañas, en "una especie de santo patrón laico de los republicanos españoles errantes, pertrechados con la permanencia de su inspiración y sus ideales" (Cabañas, 2010: 25). Dicha imagen queda sintetizada por Federica Montseny que, al introducir su obra El éxodo. Pasión y muerte de españoles en el exilio, con numerosos testimonios orales, se refiere a ellos como:

(...) eternos Quijotes, constantes caballeros de todos los ideales, combatientes de todas las contiendas, hay en nosotros demasiado orgullo y demasiada conciencia de nuestra grandeza para pensar en cobrar lo que no tiene precio (Montseny, 1977: 12).

O bien:

Desarraigados, sin hogar ni patria; cubiertos de harapos, de piojos y de sarna; ensangrentados y vencidos; con el cuerpo maltrecho y el alma transida, como don Quijote dentro de la jaula, la obstinación magnífica, la esperanza victoriosa, la energía sombría y la risa luminosa nos han salvado y nos salvan, nos salvarán siempre (Montseny, 1977: 13).

En algunos artistas, el tema del caballero andante fue fundamental durante su exilio. Es el caso del logroñés Augusto Fernández (Cabañas, De Haro, 
Murga y Sánchez, 2009: 357-361; Cabañas, Fernández, De Haro y Murga, 2011: 117-143).

En este sentido, el análisis de la figura del Quijote ha tenido más estudios en lo relativo al exilio en México que en Francia, aunque no se terminan de agotar las reflexiones, interpretaciones y relecturas. Nosotros encontramos algunos paralelismos. Así, hemos de destacar, por la inclusión de varias obras de Eleuterio Blasco, el Suplemento Literario de Solidaridad Obrera, que dedicó su número 551 a esta figura bajo el título «El ingenioso hidalgo don Quijote de la Mancha cumple sus 350 años». Un número mayor del habitual, con 32 páginas, correspondiente a los meses de octubre y noviembre, y con un precio más elevado, 80 francos.

Se contó con la colaboración literaria de Salvador de Madariaga, Luis Nicolau d'Olwer, Marcel Bataillon, Andrés María del Carpio, Pedro Voldemar, J. Beckermann, J. Ferrater Mora, Jerónimo del Paso, J. Ferrándiz Alborz, José Antonio Cuesta, Waldo Frank, Juan Ferrer, José Ortega y Gasset, Francisco Frank o Luis Araquistáin. Artículos que fueron acompañados por obras, entre otros, de A. Sancho, Bartolí, Téllez, Peinado, Argüello, Menéndez, Pelayo y Blasco Ferrer. Además recogía dicho número varias páginas dedicadas a la bibliografía del Quijote en España y en el extranjero, así como de «La presentación tipográfica de la primera edición», «Las ilustraciones españolas del Quijote», «Las ilustraciones de Gustavo Doré», «El Quijote visto por los extranjeros», «El Quijote visto por los españoles», «Consejos de don Quijote a Sancho», «Fechas importantes de la vida de Cervantes», «Resumen estadístico de las ediciones del Quijote en lenguas diversas», etc.

Las obras de Blasco Ferrer acompañaron tres artículos de dicho especial: el artículo de Ferrándiz Alborz «Cervantes... y don Quijote», con la escultura El hidalgo y su escudero (1955: 3); el de Nicolau d'Olwer «Valor de Cervantes en la literatura universal», con Visión de don Quijote (1955: 8); y el artículo de J. Chicharro de León «El episodio de los galeotes», con La muerte del hidalgo (1955: 27).

Un ejemplar parangonable al que la revista del exilio español mexicano Las Españas, dedicó en su n. ${ }^{\circ} 5$ extraordinario del mes de julio de 1947, en el aniversario del nacimiento de Cervantes. En el mismo hallamos la presencia de textos de Luis Nicolau de Olwer, Enrique González Martínez, Pedro Salinas, Agustín Millares Carlo, Juan José Domenchina, Daniel Tapia, Benjamín Jarnés, Luis Santullano, Josep Renau, Paulita Brook, Gallegos Rocafull, Juan Gil Albert, Ramón Gaya, Honorato de Castro, Jean Camp, Julio Luelmo, José Enrique Rebolledo y Jesús Bal y Gay; además de ilustraciones de Manuela Ballester, Jomi García Ascot, Carlos Marichal o Josep Renau. También hubo reconocimientos en otras publicaciones mexicanas, como Los Cuatro Gatos o los actos desarrollados por la Unión de Intelectuales Españoles.

Ya en el número inaugural de Las Españas, en 1946, José María Gallegos Rocafull (1946: 3) identificaba a los exiliados con el idealismo del personaje, advirtiendo que no sabía si estaban «más cuerdos o más locos que él», rememorando el sueño exiliado de «paz, de amistad y de concordia, que añoraba 
nuestro caballero». Una revista que afirmaba la defensa de la libertad a través de la independencia, y cuyos temas en torno al Quijote serán tratados de forma heterodoxa, aunque predominará la impronta de las circunstancias en que viven los exiliados (Piñero, 2005).

Pero el tema de don Quijote y Cervantes fue denominador común en muchas otras publicaciones francesas. Así también apareció la «publicación de humor y combate» Don Quijote, en Rodez, en junio de 1946 y hasta marzo de 1947, donde la socarronería de Sancho destacaba frente a las vicisitudes tempestuosas del hidalgo caballero; el Boletín de la Unión de Intelectuales Españoles, que publicó en 1947 un monográfico dedicado al aniversario de Cervantes, ilustrado con obras de Pedro Flores, Joaquín Peinado, Hernando Viñes y Lalo Muñoz; o Méduse, cabecera aparecida en Pau y dirigida por el poeta Jacinto-Luis Guereña y con Jean Cassou como presidente de honor, que anunció la aparición de su número 5 dedicado íntegramente a Cervantes (Risco, 1976: 121-122 y 126-127; VV.AA., 1947).

Reflexiones intelectuales, literarias y artísticas que contribuyeron a interiorizar la figura de don Quijote como icono «exílico», que ejemplifican la existencia de temas comunes, como es la figura del hidalgo manchego, poniéndose en contacto literatura, arte y pensamiento del exilio ${ }^{3}$.

\section{LOS «QUIJOTES» DE BLASCO FERRER}

La figura de don Quijote en la obra de Blasco reaparece como tema en varias ocasiones, separadas por el tiempo, durante su largo exilio en Francia: «todos son verdaderos pero distintos Quijotes» (Delgado, 1959). Para ello utilizará diferentes procedimientos artísticos: forja, soldadura, pintura o dibujo.

Ya en el Salón de Arte Libre de 1946 presenta la escultura en hierro Don Quichotte, donde el estilizado caballero, lanza en ristre, marcha lento seguido por su inseparable escudero, orondo, que parece otear el horizonte. Al crítico del periódico Apollo no le convenció, viéndolo más como obra de humorista que como escultura: «Le 'Don Quichotte' en zinc de Blasco Ferrer vaut en tant qu'oeuvre d'humoriste, mais non comme sculpture. La sculpture est un rythme de formes» (Anónimo, 1946).

El artista aragonés representará a El hidalgo y su escudero, siguiendo este mismo modelo, a mediados de los años 50, donde observamos un cambio técnico en el trabajo del metal con un mayor uso de la soldadura y un aumento del grosor de la chapa de hierro, característica esta que define su obra desde finales de los años 40, superadas las dificultades económicas de los primeros años en el exilio. Atrás quedarán las esculturas realizadas en una única plancha que dobla hasta conseguir el resultado final tras prever en dis-

3. Véase sobre estas relaciones con el Quijote los textos de Cabañas (2010: 25-29) y Mainer (2006). 
tintos bocetos en papel el resultado final, en un trabajo que recuerda la técnica de la papiroflexia.

Blasco inmortalizó al caballero andante de nuevo en 1956. Este Don Quijote, que presenta por primera vez en el Salón de Artistas Independientes de ese año, tiene también un simbolismo personalísimo, cuidando minuciosamente los detalles. Este está hecho con herraduras de caballos, de forma que Rocinante está unido a don Quijote, formando parte sustancial de él, «más centauro que un centauro» (Delgado, 1959). La originalidad de la obra radica en el uso de herraduras como definidoras de la composición. Estas conforman el tronco, cuello, orejas y bigote. Esta escultura exige una visión frontal. Conforme la abandonamos perdemos el sentido simbólico de la obra para detenernos en el ensamblaje de hierro, en la técnica. Es la luz, la que penetra en sus ojos de repentina lucidez, por su boca, por los espacios, la protagonista. Es ella la que coadyuva con el hueco y nos sugiere el idealismo del personaje.

En las mismas fechas realiza el lienzo Don Quijote, de faz iluminada por la locura sublime de un redentor imaginario, una obra trabajada siguiendo el facetamiento característico de su obra tridimensional y con una picassiana pátina neocubista.

Sin embargo, en ninguna alcanza la altura técnica y simbólica de El último suspiro de don Quijote, reconocida por crítica y público (y especialmente apreciada por el propio artista), que además sintetiza una de las más importantes características de las creaciones de Blasco, el gesto, que se manifiesta en su máxima expresión en las obras de madurez que realiza en París desde su llegada.

Nos cuenta en sus memorias Virgilio Botella, en aquel entonces jefe de los Servicios Administrativos del Gobierno de la República en el exilio, que con motivo de la celebración del primer 14 de abril, los magníficos salones de la avenida Foch ${ }^{4}$, sede del Gobierno de la República ${ }^{5}$, se decoraron con pinturas y esculturas de artistas españoles en el exilio:

4. La Sede oficial del Gobierno de la República se estableció en un elegante edificio, en el 35 Avenue Foch, que le había cedido el Gobierno francés tras incautárselo a sus propietarios, antiguos colaboracionistas. En 1960 la resolución del pleito entablado por estos a su favor, obligó al Gobierno de la República a trasladarse a un pequeño local alquilado en el 56 del boulevard Jean Jaurés, en Boulogne-Billancourt, a las afueras de la ciudad.

5. Durante los años de la Segunda Guerra Mundial, la actividad política de los exiliados se trasladó de Francia a México, donde se organizó la Diputación Permanente de las Cortes en septiembre de 1940, a instancias del JARE, y se dieron los primeros pasos para la reconstrucción de las instituciones republicanas. Recordemos que junto a la Unión Soviética, México había sido el país que desde el principio de la guerra prestó ayuda continuada a la República. Este apoyo tenía su razón de ser en las características del régimen presidido por Lázaro Cárdenas, y que se basaba en el programa de reformas sociales recogidas en la Constitución de 1917. Al llegar al poder en diciembre de 1934, con el apoyo del Partido Nacional Revolucionario, emprendió una serie de reformas en la ayuda de las organizaciones obreras. Esto explica la simpatía del Gobierno de México por la causa republicana, aunque había sectores críticos en la opinión pública. A lo largo de la guerra, México ayudó de distintas maneras a la República, y tras la derrota acogió a cerca de 22.000 refugiados entre 1939 y 1948, destacando políticos, intelectuales y profesionales liberales. En México se proclamó presidente inte- 
Entre ellas llamó especialmente la atención de los asistentes, hasta de la prensa de París, un hierro forjado de Blasco Ferrer titulado El último suspiro de don Quijote, lleno de emotividad y patetismo (Botella, 2002: 118-119).

Asistieron a esta recepción diplomática, según nos cuenta Virgilio Botella, destacadas personalidades de la política francesa, como León Blum, Paul Boncour y Hedouar Herriot, tres ex-presidentes del Consejo de Ministros de Francia y el último presidente en ejercicio de la Asamblea Nacional francesa; varios ministros del Gobierno de Francia; las representaciones diplomáticas de los países que habían reconocido al Gobierno Republicano en el exilio; líderes de distintos partidos políticos afines; altos funcionarios; profesores entre ellos Jean Sarrailh, rector de la Universidad de la Sorbona-; escritores como Albert Camus, Mauriac, Claude Aveline; miembros de todas las profesiones liberales y representantes de la prensa francesa e internacional, que dieron amplias informaciones gráficas y escritas sobre el acto (Botella, 2002: 118-119).

No deja de sorprendernos la temprana fecha sugerida por Botella (1946) para El último suspiro de don Quijote, ya que no aparece en ningún catálogo hasta 1950, año en que se expone en la Galería Jean Lambert. No la expuso Blasco, de ser esta fecha correcta, en su segunda individual, en la galería Bosc en 1948, lo cual es extraño. Esta referencia de Virgilio Botella, pensamos ha de tratarse de un recuerdo posterior del autor que enmarca en 1946, por lo que mantenemos la cronología de esta pieza hacia 1950. Hemos consultado a Alicia Alted, que editó y prologó estas memorias, pero no recuerda a qué exposición se puede referir ni al año concreto, aunque sí nos ha concretado que el primer 14 de abril de Botella en París tuvo lugar en 1946. En la tercera exposición parisina de Eleuterio Blasco, celebrada en la Galería Lambert en $1950^{6}$, mostró por primera vez esta obra, considerada para muchos su obra maestra.

Allá donde se expuso, el público quedó entusiasmado por su emotiva expresión, su profundidad de alma y pureza de estilo. Blasco parece haber volcado en esta escultura todo el dolor de España «impuesto por cínicos y cretinos, por aventureros que en nombre de la justicia dejan morir al pueblo de hambre y miseria» (Blasco Ferrer, s.f.: 113). Por ella, hoy expuesta en la

rino de la República Española, en Sesión de Cortes, a Diego Martínez Barrio, que designó a José Giral Presidente del Consejo de Ministros. Una vez formado el Gobierno de Giral, se procedió a la reconstrucción de la administración republicana, y con el fin de desarrollar mejor su política de cara a España, el Gobierno decidió su traslado a París tras la aceptación del Gobierno francés. Así, el 8 de febrero de 1946 llegaba a la ciudad el Presidente del Consejo de Ministros, y un mes más tarde el Presidente de la República. Diremos que el primer país en reconocer a la República fue México, el 28 de agosto de 1945, luego Guatemala, Panamá (en septiembre), Venezuela (en noviembre). Entre abril y noviembre de 1946 fue reconocida por Polonia, Yugoslavia, Rumanía, Checoslovaquia, Hungría, Albania y Bulgaria. De todos ellos solo México y Yugoslavia lo mantuvieron hasta 1977. Sobre la República en el exilio véanse por ejemplo los textos de Alicia Alted (2001: 239-254) y Sánchez Cervelló (2011).

6. Galerie Jean Lambert (22 Place Vendôme), del 14 de abril al 5 de mayo de 1950. 
Sala Eleuterio Blasco Ferrer del Parque Cultural de Molinos (Teruel), le ofrecieron suculentas ofertas desde el extranjero ${ }^{7}$, si bien nunca pensó en desprenderse de esta pieza, permaneciendo siempre en la colección del artista, a pesar de las acuciantes necesidades económicas, hasta apenas un par de meses antes de su fallecimiento ${ }^{8}$.

Aquí, la contracción física del rostro y de la mano logra un patetismo y una sensación de hundimiento de toda esperanza. Dice Francisco Ferrándiz Alborz:

La mano es un esfuerzo por abrir el pórtico del más allá, por donde las almas vuelan a la eternidad. Pero el gesto es un interrogante ante el misterio que se avecina. ¿Habrá que despedirse de este mundo de aventuras desventuradas para entrar en el reino de las desventuras venturosas? ¿Valdrá la pena resignarse a morir tranquilamente en busca de la paz soñada? ¿No habrá otra realidad más susceptible de perfección que la del continuo choque de nuestro deseo contra bachilleres, curas y marqueses vacíos de aventura y ensueño?

En este postrero suspiro, don Quijote no muere devotamente para entrar en el mundo invisible del reposo, sino que muere a lo Caballero Andante, a lo Triste Figura, poniendo gesto duro al misterio, sin dejarse arrebatar la sal de su desesperación ante la injusticia. No es del todo cierto que su desventura quede manifiesta, muriendo cuerdo quien ha vivido loco. Vivió y murió con la santa cordura de la indignación, que los bellacos confunden con la locura. Así lo vemos, indignado hasta la muerte, en la eterna transformación simbólica con que nos muestra el fuego, el aire, el hierro fundido por la mano cálida, orfebrería y arte (Ferrándiz Alborz, 1951: s.n.).

Si nos fijamos en él, sus ojos están hechos de espacio libre. La posición dolorosa de la boca, donde podemos ver sus dientes, está marcada por el vacío. La mano y todo el conjunto dan la impresión de una tremenda tristeza, no tanto por su vida que se va, sino por un gran sueño quijotesco que se va a apagar para siempre:

Para encontrar otra mano como la del Quijote en agonía -señalaba Gregorio Oliván- tendríamos que volver al Greco, que tuvo a su favor la técnica más dulce de la pintura, y Cervantes debió soñar así para el último capítulo de su obra, la agonía de su héroe. Esta cabeza de hierro «suda» la muerte; el metal se hace cera, las quedejas se pegan sobre las sienes, la comba de la frente da suelta al alma (Oliván, 1950: 1).

7. Especialmente insistente fue Oscar Ghez, Presidente-Fundador del Petit Palais de Ginebra, museo que ya poseía varias obras en hierro del aragonés. Se conservan numerosas cartas en torno a esta cuestión desde 1986. Archivo particular (Barcelona).

8. Documento de compraventa firmado el trece de mayo de 1993 por la obra El último suspiro de Don Quijote, reunidos el Ayuntamiento de Molinos (Teruel) representando por su alcalde Orencio Andrés Huesa y Eleuterio Blasco Ferrer. En el mismo se estipula un precio de 5.000.000 de ptas. pagaderas en una entrega inicial de 200.000 pts., y una pensión vitalicia mensual de 60.000 ptas. Blasco apenas cobró una mínima parte del dinero ya que poco después, en la media noche del miércoles 28 de julio de ese año, 1993, fallecía en la Residencia para la Tercera Edad de Alcañiz, donde vivió tan solo los dos últimos meses de vida. Archivo Ayuntamiento de Molinos. 
En un texto mecanografiado del discurso de presentación que el escultor holandés L. P. J. Braat dio en la inauguración de la exposición de Blasco en la galería Le Canard de Ámsterdam, el artista anotó en la parte inferior, a mano:

$\mathrm{Al}$ hacer la presentación el escultor Braat, una señora miraba mi escultura El último suspiro de don Quijote y cayó desmayada al suelo, y a otras personas les hizo llorar, quizás pensando en la Guerra Civil ${ }^{9}$.

Y en Hierro candente señala que:

Un día recibí en mi estudio a un Príncipe. Al despedirse me dijo: «Perdóneme que le felicite», llorando delante de la obra El último suspiro de don Quijote. No me extrañó, pues no era la primera persona que esta escultura en hierro forjado había penetrado en lo más profundo de sus corazones. Príncipes también del intelecto y del trabajo (Blasco Ferrer, s.f.: 114).

Es, posiblemente, la obra más reveladora del drama del exilio a Francia a través de la figura de don Quijote, como la gran tela-mural que Antonio Rodríguez Luna pintara en 1973, Don Quijote en el exilio, lo es para el exilio mexicano. Esta se halla en la sala número cuatro del Museo Iconográfico del Quijote en Guanajuato (México). En ella, en un paisaje desolado de azules oscuros y grises, en una ambientación incierta y triste, vemos al Caballero de la Triste Figura sobre un escuálido Rocinante con los ojos vendados, vencido, cansado, sin rumbo. Tras él un cortejo de españoles exiliados, peregrinos, abatidos, con hombros caídos, que miran al suelo. Al frente León Felipe, Antonio Machado, Juan Ramón Jiménez, José Bergamín... o Eulalio Ferrer, que habló del Quijote como «el de un amante de la libertad, el de una encarnadura inobjetable e ideal del universo español, el de una gratitud desde las entrañas de la hermandad» (Redondo, 2009: 213). Protagonistas de una ventura quijotesca que en muchos casos no tuvo retorno, pero expresión a su vez del espíritu de libertad y de su universalidad. Gaya Nuño señaló sobre el Quijote que «es algo así como un gran portalón abierto de par en par, no al paisaje, no a los seres, ni a las ideas, ni a la fantasía, sino abierto de par en par al vacío» (Gaya, 1947: 10, 13).

Blasco siempre contempló El último suspiro de don Quijote, como una criatura que hubiera parido, criatura de sangre, de carne y de huesos:

Si hoy me propusieran realizar esta obra, no podría, y es que las obras de arte no se repiten. Además la realicé en momentos difíciles y pensando en el destino de mi Patria (Blasco, s.f.: 113).

Esta escultura en hierro sintetiza con maestría todo ese deseo para los exiliados que es el anhelo de libertad, que se da en don Quijote, constituyéndose en paradigma simbólico de una actitud ante la vida, donde los valores

9. Traducción del discurso realizado por el escultor L. P. J. Braat en la galería Le Canard, Ámsterdam, en 1952, con anotaciones manuscritas. Archivo particular (Barcelona). 
del hombre se han de medir por el ideal que persiguen, por encima de las repercusiones de su acción, que en este caso supondrá sacrificar vivir en su tierra en pro de la libertad (Abellán, 2003: 545-553): «Bien podrán los encantadores quitarme la ventura pero el esfuerzo y el ánimo es imposible» ${ }^{10}$.

Como escribiera Juan de la Pena ${ }^{11}$ :

Padre don Quijote

que estás en los Cielos

líbranos del odio y el abandon o.

Padre don Quijote,

líbranos, Señor,

de la cobardía

y el deshonor.

Padre don Quijote

altísimo y perfectísimo

líbranos de una vida

sin ideal (Stein, 1983, 109).

\section{BIBLIOGRAFÍA CITADA}

Abellán, José Luis (2003). «Don Quijote como símbolo», en Alicia Alted y Manuel Lluisa (dir.). La Cultura del exilio republicano español de 1939, Actas del Congreso Internacional Sesenta años después. Madrid: UNED, I, pp. 545-553.

Alted, Alicia (2012). «El exilio de los anarquistas», en Julián Casanova (coord.), Tierra y Libertad. Cien años de anarquismo en España. Barcelona: Crítica, pp. 167-190.

Alted, Alicia (2005). La voz de los vencidos. Madrid: Aguilar.

Alted Vigil, Alicia (2001). «La Segunda República en el exilio», en M. ${ }^{a}$ Fernanda Mancebo, Marc Baldó y Cecilio Alonso (ed.). Seixanta Anys Després. L'Exili Cultural de 1939. Valencia: Universitat de València, 1, pp. 239-254.

Blasco Ferrer, Eleuterio (s.f.). Hierro candente, Autobiografía manuscrita inédita, cuaderno 2.

Botella Pastor, Virgilio (2002). Entre memorias. Las finanzas del Gobierno Republicano español en el exilio. Alicia Alted Vigil (ed.). Sevilla: Editorial Renacimiento.

Cabañas Bravo, Miguel (2010). "Quijotes en otro suelo, artistas españoles exiliados en México», en Miguel Cabañas, Dolores Fernández, Noemí de Haro e Idoia Murga (coord.). Analogías en el arte, la literatura y el pensamiento del exilio español de 1939. Madrid: CSIC, pp. 25-50.

Cabañas Bravo, Miguel, De Haro, Noemí, Murga Idoia y Sánchez, Mario (2009). "Estampas de don Quijote en el exilio. Obra gráfica de Augusto Fernández", Anales cervantinos. 41, pp. 357-361.

Cabañas, Miguel, Fernández, Dolores, De Haro, Noemí y Murga, Idoia (2011). «Augusto Fernández, ilustrador de Don Quijote en el exilio mexicano», Anales Cervantinos. 43, pp. 117-143.

Caudet, Francisco (1997). Hipótesis sobre el exilio republicano de 1939. Madrid: Fundación Universitaria Española. 
Mainer, José-Carlos (2006). Moradores de Sanseña (Lecturas cervantinas de los exiliados republicanos de 1939). Valladolid: Junta de Castilla León-Universidad de Valladolid.

Montseny, Federica (1977). El éxodo. Pasión y muerte de españoles en el exilio. Barcelona: Galba Edicions.

Pérez Moreno, Rubén (2014). Eleuterio Blasco Ferrer (1907-1993). Trayectoria artística, Tesis Doctoral [en línea] Zaragoza: Departamento de Historia del Arte de la Universidad de Zaragoza. Accesible en: <http://zaguan.unizar.es/record/13518/> (17.11.2014).

Piñero Valverde, José María (2005). «Las Españas y la presencia del Quijote entre los exiliados en México», en La Literatura y la Cultura del exilio republicano español de 1939 [Archivo de ordenador]: Actas del IV Coloquio Internacional: Hotel Las Lagunas, del 16 al 19 de julio de 2002 San Antonio de Baños, La Habana, Cuba. Edición digital: Biblioteca digital Miguel de Cervantes. Accesible en: <www.cervantesvirtual. com> (17.11.2014).

Redondo Benito, Fernando (2009). «Don Quijote en el exilio. Un caballero trasterrado: Eulalio Ferrer Rodríguez», Revista de Estudios Cervantinos. 12, pp. 211-224.

Risco, Antonio (1976). «Las revistas de los exiliados en Francia», en José Luis Abellán (dir.), El exilio español de 1939. Madrid: Taurus, vol. 3, pp. 93-150.

Rubio, Javier (1974). La emigración española a Francia. Barcelona: Ariel.

Rubio, Javier (1977). La emigración de la guerra civil de 1936 a 1939. Historia del éxodo que se produce con el fin de la II República. Madrid: Librería San Martín.

Sánchez Cervelló, Josep (2011). La II República en el exilio (1939-1977). Barcelona: Planeta.

Stein, Louis (1983) Más allá de la muerte y exilio. Los republicanos españoles en Francia, 1939-1955. Barcelona: Plaza y Janés.

\section{PRENSA PERIÓDICA}

Anónimo (1946). Apollo. París: 15 de julio.

Chicharro De León, J. (1955). «El episodio de los galeotes», Solidaridad Obrera. Suplemento Literario. n. ${ }^{\circ}$ 551-22-23, París, p. 27.

D'Olwer, Nicolau (1955). «Valor de Cervantes en la literatura universal», Solidaridad Obrera. Suplemento Literario. n. ${ }^{\circ}$ 551-22-23, París, p. 8.

Delgado, Rafael (1959). «Eleuterio Blasco-Ferrer. El escultor que hace obra de arte con el hierro», Índice Literario de El Universal. Caracas, 25 de junio de 1959.

Ferrándiz Alborz, F. (1955). «Cervantes y... Don Quijote», Solidaridad Obrera. Suplemento Literario. n. ${ }^{\circ}$ 551-22-23, París, p. 3.

Ferrándiz Alborz, F. (1951). «El escultor en hierro E. Blasco Ferrer», El Día. Montevideo, 25 de marzo $(\mathrm{s} / \mathrm{n})$.

Gallegos Rocafull, José M. ${ }^{\mathrm{a}}$ (1946). «A vueltas con el tiempo», Las Españas. n. ${ }^{\circ}$ 1, p. 3.

Gaya, Ramón (1947). «Portalón de par en par», Las Españas. n. ${ }^{\circ}$ 5, julio de 1947, pp. 10-13.

Oliván, Gregorio (1950). «Blasco Ferrer, artista multiforme», CNT. n. ${ }^{\circ}$ 265, París, 7 de mayo, p. 1.

VV.AA. (1947). Boletín de la Unión de Intelectuales Españoles. N. 36 y 37, París.

VV.AA. (1955). Suplemento Literario de Solidaridad Obrera, Especial «El ingenioso hidalgo don Quijote de la Mancha cumple sus 350 años». N. ${ }^{\circ}$ 551-22-23, París, octubrenoviembre. 


\title{
Resumen
}

En el siguiente artículo analizaremos las representaciones de don Quijote realizadas en el exilio parisino por el artista aragonés Eleuterio Blasco Ferrer (Foz-Calanda, Teruel, 1907-Alcañiz, Teruel, 1993). Una de sus esculturas, El último suspiro de don Quijote, alcanzará una notable popularidad, convirtiéndose en verdadero símbolo del exilio republicano.

Palabras clave: Eleuterio Blasco Ferrer; exilio republicano; don Quijote; arte aragonés.

Title: Don Quixote and the Exile: The representation of the Knight Hidalgo in the Plastic of the Aragonese Artist Eleuterio Blasco Ferrer.

\begin{abstract}
In the following article we are going to analyse the artworks of Don Quixote created in the exile by the Aragonese artist Eleuterio Blasco Ferrer (Foz-Calanda, Teruel, 1907-Alcañiz, Teruel, 1993). One of his sculptures, The last breath of Don Quixote, will reach high popularity, becoming a true symbol of the Republican exile.
\end{abstract}

Key words: Eleuterio Blasco Ferrer; Republican exile; Don Quixote; Aragonese art. 